allergic type of drug fever. It is quite possible that this reaction to the drug could explain why the temperature in the cases treated by Drs. McHardy and Schonell with the higher dose became normal later than those treated with the lower.-I am, etc.,

Roslagstulls Hospital,

JUSTUS STRÖM

1 Ström, J., Acta Paediatrica Scandinavica, 1968,

\section{Hazard of Ultrasonic Detection of Deep} Vein Thrombosis

SIR,-I was interested in the letter from Drs. J. N. Brown and A. Polak (13 January, p. 108). I have always been dubious about squeezing the calf in such a case in order to determine whether there was a flow, and recently $I$ have been putting the cuff on the foot. This enables detection of flow to be determined either at the popliteal level or the groin without any difficulty and with the least possible danger. Squeezing the foot with the automatic cuff is to my mind a much more logical approach in the detection of deep vein thrombosis.-I am, etc.,

D. W. BRACEY

District Hospital, Peterborough

\section{Actinomycin D for Wilms's Tumour}

SIR,-Although it is widely accepted that actinomycin $\mathbf{D}$ should be given in conjunction with surgery and radiotherapy in the initial treatment of Wilms's tumour, a number of reports have cast doubt on its value. $^{1-3}$ Stone and Williams ${ }^{2}$ found that when it was given at and after nephrectomy seven out of 13 patients remained free of metastases, whereas 12 out of 14 remained free of metastases when it was not given.

In the entire Birmingham Region during the years 1965-9 inclusive a total of 48 cases of Wilms's tumour were registered, all in patients under the age of 15 years. Excluding two cases of stage I tumour found incidentally after accidental death, the threeyear survivals free of tumour were as follows:

Patients Receiving Actinomycin $D$
as Part of Their Initial Treatment

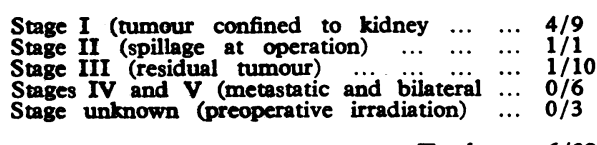

Total ... $6 / 29$

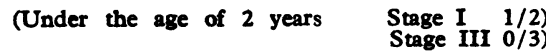

Patients Not Receiving Actinomycin D

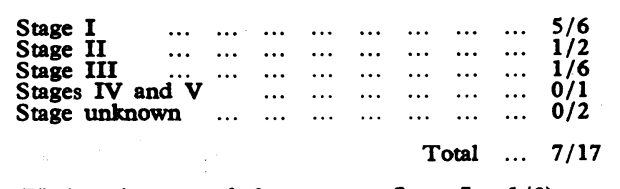

(Under the age of 2 years $\begin{aligned} & \text { Stage I } 1 / 2 \text { ) } \\ & \text { Stage III } 1 / 2 \text { ) }\end{aligned}$

It can be seen that only in stage II were the results better for patients receiving actinomycin $\mathrm{D}$, and the numbers here are so small as to be meaningless. In all other stages the patients receiving actinomycin D fared as badly as or worse than those who did not receive the drug.

I believe that these results, taken in conjunction with those reported by the authors quoted above, warrant a properly controlled trial with random allocation between actinomycin D or no chemotherapy as part of the initial treatment of Wilms's tumour.-I am, etc.,

Queen Elizabeth Hospital,

H. W. C. WARD

1 Ledlie, E. M., Mynors, L. S., Draper, G. J. and Gorbach, P. D., British Medical fournal, 1970, 4, 195

(Philadelphia) 1967, 20, 96.

Stone, J., and Williams, I. G., Clinical Radiology,
$1969,20,40$.

\section{Anaesthesia by Acupuncture}

SIR,-Before you relegate acupuncture anaesthesia (or analgesia) to the position of a lost cause, I wish to point out that in the original letter ( 5 August, p. 352), signed by four of the 10 British doctors who visited China in April 1972, we were primarily interested in having the extraordinary phenomenon of major operations under anaesthesia (or analgesia) induced by acupuncture investigated by a competent team of scientists. Psychiatrists could be included to make sure if only Chinese peasants or Maoists are susceptible, and to measure the level of suggestion or hypnosis

We came to the conclusion that Chinese doctors are honest, and they freely admitted to using western drugs and tranquillizers as adjuvants when required. Dr. I. Capperauld (28 October, p. 232) describes cases of gastrectomy (which most of us did not see) in which evidently fairly large doses of adjuvants were used. On the other hand, we all saw other major operations on patients of whom some had very small doses of sedatives, but others had no sedatives at all

There is obviously room for the whole spectrum from complete scepticism to total acceptance. The essential points are that the patients were fully conscious, not even drowsy, and that the phenomenon works in most cases. The Chinese admit that about $20 \%$ of people are unsuitable candidates However, many patients who could not otherwise undergo major operations are able to have them and with minimal physiological disturbance.-I am, etc.,

SIDNEY HAMILTON

British High Commission Hospital

\section{Dangers of Diazoxide}

SIR,-It is not clear from Dr. P. Kuan's letter (13 January, p. 114) whether his patient with malignant hypertension who developed skin eruptions and thrombocytopenia received diazoxide orally or intravenously. As ampoules of diazoxide for intravenous injection contain $300 \mathrm{mg}$ of the drug, the stated daily dose of $500 \mathrm{mg}$ suggests that the oral route may have been employed.

Both rashes and haematological reactions including thrombocytopenia have been recorded during oral diazoxide therapy for hypoglycaemia..$^{1-3}$ Although these have not so far been reported with short-term intravenous administration, the possibility of such adverse effects occurring after repeated injections cannot be excluded ${ }^{4}$ and investigators are advised to carry out regular haematological checks where courses of diazoxide injections last more than a few days, or where continued oral therapy is used.-I am, etc.,

Allen and Hanburys Ltd.,
Ware, Hlerts

B. H. BOEREE

1 Drash, A., Kenny, F., Field, J., Blizzard, R., Langs, H., and Woiff, F., Annals of the New York Academy of Sciences, 1968, 150, 337. Worf, F., Hirsch, E., Wales, J., and Viktora, J., Annals of the 3 Wales, J. K., and Wolff, F., Lancet, 1967, 1, 53.
4 Drugs, 1971, 2, 78.

\section{Availability of Cadaveric Kidneys for} Transplantation

SIR,-I was particularly interested in the paper by Mr. David L. Crosby and Dr. W. E. Waters (11 November, p. 346). Recently a survey was carried out among the staff of this hospital with regard to renal transplantation. A total of 196 persons participated in the survey ( 9 senior medical students, 11 doctors, 20 paramedical staff, and 156 nurses). Details of the questions and answers are published elsewhere ${ }^{1}$

The most interesting findings were as follows: (1) Slightly more than $50 \%$ of doctors, nurses, and medical students were willing to donate their own kidneys after death, yet $70 \%$ of the same people were not agreeable to the use of the kidneys of someone close to them for transplant purposes. Contrary to popular belief, religion did not appear to play an important part in refusal except in Muslims. The two commonest reasons put forward were fear of causing distress to the next-of-kin and a wish to be "buried in one piece." (2) All except Muslims favoured transplantation as a therapeutic procedure. (3) With the exception of doctors, none of those questioned favoured a change in the law to make it easier to obtain organs from the dead for transplantation.

I believe that this is the first survey of its kind in a developing country with a multiracial and multireligious society and its implications are important. This could possibly explain the slow progress that renal transplantation has made in this part of the world. In the final analysis, it is obvious that for any measure of success to be achieved in a transplant programme, a correct attitude of mind has to be created. This could only come about with better education and dissemination of relevant information through the mass media.-I am, etc.,

Thomson Road General Hospital,

P. H. Feng 1 Feng, P. H., Chen, V., and Lee, Y. K., Asian

\section{Management for Health}

SIR,-Mr. R. J. Maxwell's distinguished paper (20 January, p. 160) makes interesting reading but does not provide evidence for his statement that "all these are unmistakable signs that management performance is poor." The N.H.S. has been kept going since 1948 in the face of many difficulties, which must indicate some success in managing. However, the main factors have been the goodwill and traditional loyalties carried forward from the long previous life of that 